\title{
Reactive, Inelastic, and Dissociation Processes in Collisions of Atomic Nitrogen with Molecular Oxygen
}

\author{
Fabrizio Esposito*,1, Iole Armenise, \\ ${ }^{1}$ CNR ISTP, Via Amendola 122/D, 70126 Bari, Italy \\ E-mail: fabrizio.esposito@cnr.it, iole.armenise@cnr.it
}

\section{Supporting Information}

Table S1. Coefficients of polynomial fit of the decimal logarithm of reactive rate coefficient (in $\mathrm{cm}^{3} / \mathrm{s}$ ) as a function of final vibration in the range $v^{\prime}=0-9$ and temperature in the range $200 \mathrm{~K}-1000 \mathrm{~K}$ :

$\mathrm{f}\left(v^{\prime}, T\right)=\sum_{i, j=0-5} a_{i j} v^{\nu^{i}} T^{j}, \mathrm{R}_{\text {react }}\left(v^{\prime}, T\right)=10^{\mathrm{f}\left(v^{\prime}, T\right)}$

with:

$\mathrm{a} 00=-31.7856$

$\mathrm{a} 01=-2.38785$

$\mathrm{a} 02=2.51941$

$\mathrm{a} 03=-0.915124$

$\mathrm{a} 10=0.103946$

$\mathrm{a} 11=0.014007$

$\mathrm{a} 12=-0.0146947$

a13 $=0.0052902$

a20 $=-0.000273671$

$\mathrm{a} 21=-3.93603 \mathrm{e}-05$

$\mathrm{a} 22=4.08553 \mathrm{e}-05$

$\mathrm{a} 23=-1.46132 \mathrm{e}-05$

a30 $=3.851 \mathrm{e}-07$

$\mathrm{a} 31=5.76655 \mathrm{e}-08$

a32 $=-5.97883 e-08$

a33 $=2.129 \mathrm{e}-08$

$\mathrm{a} 40=-2.74532 \mathrm{e}-10$

$\mathrm{a} 41=-4.19722 \mathrm{e}-11$

$\mathrm{a} 42=4.3754 \mathrm{e}-11$

$\mathrm{a} 43=-1.55547 \mathrm{e}-11$

$\mathrm{a} 44=2.28945 \mathrm{e}-12$

$\mathrm{a} 04=0.137229$

$\mathrm{a} 14=-0.000790635$

a24 $=2.1713 \mathrm{e}-06$

a34 $=-3.14553 e-09$

a $50=7.78476 \mathrm{e}-14$

a51 $=1.19948 \mathrm{e}-14$

a52 $=-1.26009 \mathrm{e}-14$

$\mathrm{a} 53=4.48031 \mathrm{e}-15$ 
$\mathrm{a} 54=-6.58062 \mathrm{e}-16$

$\mathrm{a} 55=3.45072 \mathrm{e}-17$

$\mathrm{a} 05=-0.0073388$

$\mathrm{a} 15=4.21429 \mathrm{e}-05$

a25 $=-1.15166 \mathrm{e}-07$

a35 $=1.65981 \mathrm{e}-10$

a45 $=-1.20345 \mathrm{e}-13$

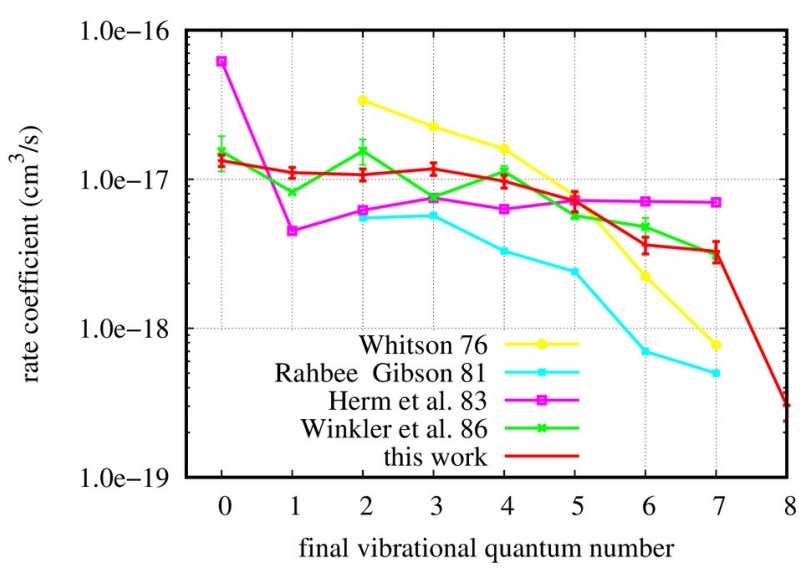

Figure S1. Comparison of reaction rate coefficients of $\mathrm{N}+\mathrm{O}_{2} \rightarrow \mathrm{NO}\left(\mathrm{v}^{\prime}\right)+\mathrm{O}$ at $T=300 \mathrm{~K}$ as obtained using the QCT method (this work, with error bars) and the experimental results by Whitson ${ }^{1}$, Rahbee and Gibson ${ }^{2}$, Herm et al. ${ }^{3}$ and Winkler et al. ${ }^{4}$ (with error bars). 


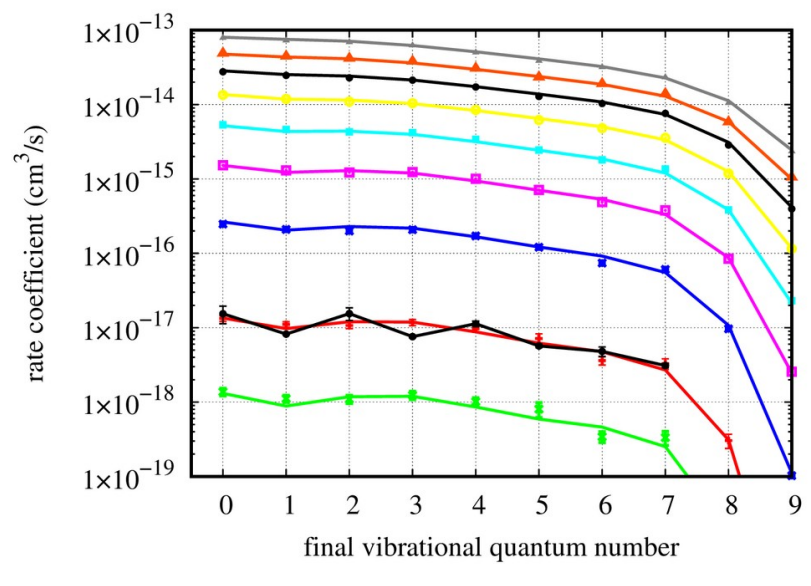

Figure S2. Comparison of reactive rate coefficients (points) as a function of final vibrational quantum number at different temperatures with the interpolation provided in this work (curves). The points and related curves are relative to $T=250 \mathrm{~K}$ (the lowest, green one), then at steps of $100 \mathrm{~K}$ from $300 \mathrm{~K}$ up to $1000 \mathrm{~K}$. At $300 \mathrm{~K}$ even the experimental values from ref. ${ }^{4}$ is shown (black thick curve).

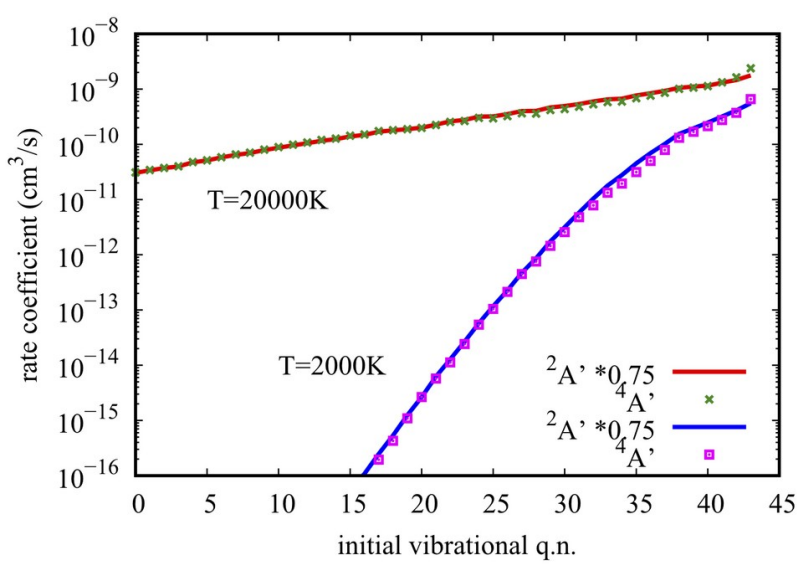

Figure S3. Comparison of dissociation rate coefficients as a function of initial vibrational quantum number calculated in this work on the ${ }^{2} A^{\prime}$ and ${ }^{4} A^{\prime} P E S s$, at two temperatures. On the ${ }^{2} A^{\prime}$ PES the result has been multiplied by 0.75 . 


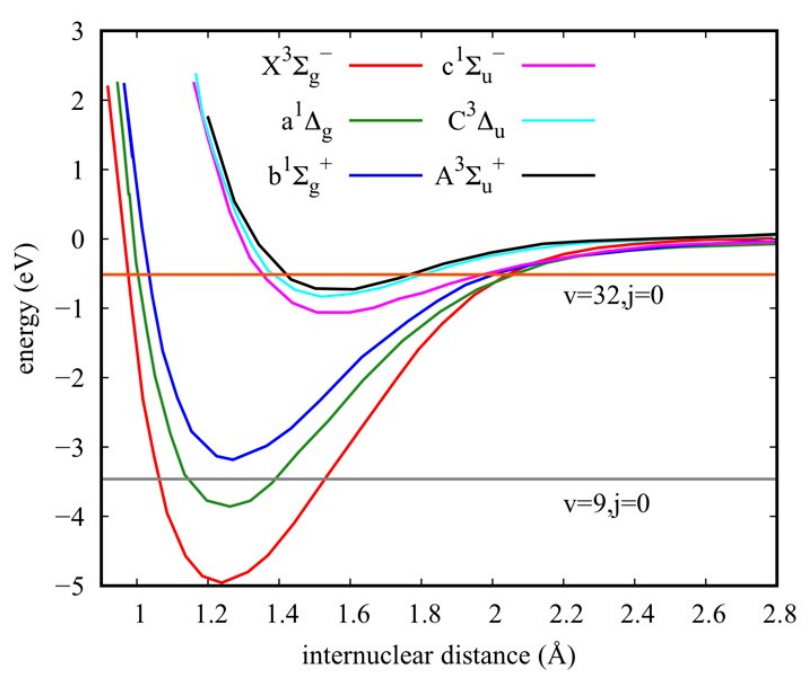

Figure S4. Electronic states of $\mathrm{O}_{2}$ of interest in the text. For the lower v-states of the ground e-state the equilibrium can possibly be established only with lowlying e-states showing at least a minimum not higher than the v-state energy. The consideration of this necessary condition does not change the thermal rate significantly, but is of importance when dealing with state-selected dissociation rate coefficients. The curves are taken by hand from ${ }^{2}$. The ground e-state in that reference appears too high by about $0.3 \mathrm{eV}$ with respect to the value found in this work, but it is not relevant in the model application. In the examples in the figure, $v=9$ of the ground e-state has an associated Nikitin factor of $(3+2) / 3$, being 2 the degeneracy of $a^{1} \Delta_{g}$. For $v=32$, the maximum value is obtained: $(3+2+1+1+6+3) / 3=16 / 3$. 
Table S2. Progressive Nikitin factor in the dissociative reaction $\mathrm{N}+\mathrm{O}_{2}(\mathrm{v})$--> $\mathrm{N}+\mathrm{O}+\mathrm{O}$

\begin{tabular}{|c|c|}
\hline $\begin{array}{c}\text { vibrational levels } \\
\text { (of the ground electronic } \\
\text { state) }\end{array}$ & Nikitin factor \\
\hline $\mathrm{v} \leq 6$ & 1 \\
\hline $7 \leq v \leq 10$ & $\frac{5}{3}$ \\
\hline $11 \leq v \leq 26$ & 2 \\
\hline $27 \leq v \leq 28$ & $\frac{7}{3}$ \\
\hline $29 \leq v \leq 29$ & $\frac{13}{3}$ \\
\hline $30 \leq v$ & $\frac{16}{3}$ \\
\hline
\end{tabular}

\section{References}

(1) Whitson, M. E.; Darnton, L. A.; McNeal, R. J. Vibrational Energy Distribution in the NO Produced by the Reaction of N(4S) with O2. Chemical Physics Letters 1976, 41 (3), 552-556. http://dx.doi.org/10.1016/00092614(76)85415-2.

(2) Rahbee, A.; Gibson, J. J. Rate Constants for Formation of NO in Vibrational Levels $\mathrm{v}=2$ through 7 from the Reaction $\mathrm{N}(4 \mathrm{~S})+\mathrm{O} 2 \rightarrow \mathrm{NO} \neq+\mathrm{O}$. The Journal of Chemical Physics 1981, 74 (9), 5143. https://doi.org/10.1063/1.441723.

(3) Herm, R. R.; Sullivan, B. J.; Whitson, M. E. Nitric Oxide Vibrational Excitation from the N(4S)+O2 Reaction. The Journal of Chemical Physics 1983, 79 (5), 2221. https://doi.org/10.1063/1.446071.

(4) Winkler, I.; Stachnik, R. A.; Steinfeld, J. I.; Miller, S. M. Determination of NO $(\mathrm{V}=0-7)$ Product Distribution from the $\mathrm{N}(4 \mathrm{~S})+\mathrm{O} 2$ Reaction Using TwoPhoton Ionization. The Journal of Chemical Physics 1986, 85 (2), 890. https://doi.org/10.1063/1.451840.

(5) Saxon, R. P.; Liu, B. Ab Initio Configuration Interaction Study of the Valence States of 02. The Journal of Chemical Physics 1977, 67 (12), 5432-5441. https://doi.org/10.1063/1.434764. 